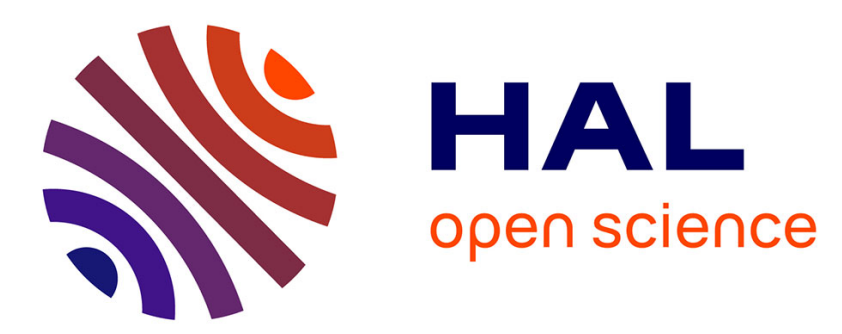

\title{
Solvothermal synthesis of BiOI microspheres: Effect of the reaction time on the morphology and photocatalytic activity
}

Adriana C. Mera, Yanko Moreno, Jean-Yves Pivan, Octavio Peña, Héctor D. Mansilla

\section{To cite this version:}

Adriana C. Mera, Yanko Moreno, Jean-Yves Pivan, Octavio Peña, Héctor D. Mansilla. Solvothermal synthesis of BiOI microspheres: Effect of the reaction time on the morphology and photocatalytic activity. Journal of Photochemistry and Photobiology A: Chemistry, 2014, 289, pp.7-13. 10.1016/j.jphotochem.2014.05.015 . hal-01019219

\author{
HAL Id: hal-01019219 \\ https://hal.science/hal-01019219
}

Submitted on 25 Mar 2016

HAL is a multi-disciplinary open access archive for the deposit and dissemination of scientific research documents, whether they are published or not. The documents may come from teaching and research institutions in France or abroad, or from public or private research centers.
L'archive ouverte pluridisciplinaire HAL, est destinée au dépôt et à la diffusion de documents scientifiques de niveau recherche, publiés ou non, émanant des établissements d'enseignement et de recherche français ou étrangers, des laboratoires publics ou privés. 


\section{Accepted Manuscript}

Title: Solvothermal synthesis of BiOI microspheres. Effect of the reaction time on the morphology and photocatalytic activity

Author: Adriana C. Mera Yanko Moreno Jean-Yves Pivan Octavio Peña Héctor D. Mansilla

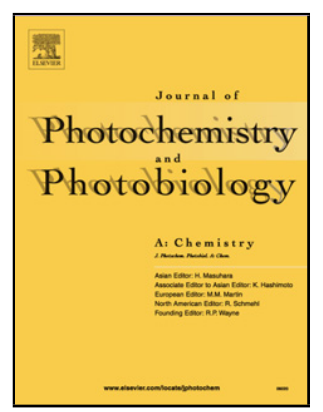

PII:

DOI:

Reference:

S1010-6030(14)00235-4

To appear in: Journal of Photochemistry and Photobiology A: Chemistry

Received date: $\quad 10-2-2014$

Revised date: $\quad 15-5-2014$

Accepted date: $\quad$ 23-5-2014

Please cite this article as: A.C. Mera, Y. Moreno, J.-Y. Pivan, O. Peña, H.D. Mansilla, Solvothermal synthesis of BiOI microspheres. Effect of the reaction time on the morphology and photocatalytic activity, Journal of Photochemistry and Photobiology A: Chemistry (2014), http://dx.doi.org/10.1016/j.jphotochem.2014.05.015

This is a PDF file of an unedited manuscript that has been accepted for publication. As a service to our customers we are providing this early version of the manuscript. The manuscript will undergo copyediting, typesetting, and review of the resulting proof before it is published in its final form. Please note that during the production process errors may be discovered which could affect the content, and all legal disclaimers that apply to the journal pertain. 


\title{
Solvothermal synthesis of BiOI microspheres. Effect of the reaction time on the morphology and photocatalytic activity
}

\author{
Adriana C. Mera ${ }^{\mathrm{a}}$, Yanko Moreno ${ }^{\mathrm{a}}$, Jean-Yves Pivan ${ }^{\mathrm{b}}$, Octavio Peña ${ }^{\mathrm{b}}$, \\ Héctor D. Mansilla ${ }^{\mathrm{a}^{*}}$
}

${ }^{a}$ Facultad de Ciencias Químicas, Universidad de Concepción, PO BOX 160-C, Concepción, Chile

${ }^{b}$ Institut des Sciences Chimiques de Rennes, UMR 6226,Universitede Rennes-1,35042, Rennes, France

\begin{abstract}
BiOI microspheres were synthesized by a solvothermal synthesis route from $\mathrm{Bi}\left(\mathrm{NO}_{3}\right)_{3}{ }_{3} 5 \mathrm{H}_{2} \mathrm{O}$, using ethylene glycol in the presence of the ionic liquid 1-buthyl-3-methylimidazolium iodide. The autoclave temperature was maintained constant at $120^{\circ} \mathrm{C}$ and the reaction time was varied from 2 to 48 hours. The obtained materials were characterized by XRD, SEM, TEM, EDS, nitrogen adsorption, FTIR and DRS. In addition, the photocatalytic activity of synthesized BiOI was evaluated in the oxidation of caffeic acid under simulated solar irradiation. Samples obtained between 12 and $24 \mathrm{~h}$ of synthesis present microsphere shapes and higher photocatalytic activity. All materials exhibit higher activities than TiO2 Evonik P25 used as standard catalyst.
\end{abstract}

Keywords: BiOI, caffeic acid, microspheres, photocatalyst, solvothermal synthesis, UV-A

*Corresponding author

Héctor D. Mansilla, Tel: 56412204600

hmansill@udec.cl 


\section{Introduction}

Selected metal oxides have been used for photocatalytic applications due to their low cost and high stability in aqueous solution [1,2].Among them, titanium dioxide and zinc oxide are the most mentioned in the literature for water and air purification testing [3-5]. Titania Evonik P25 presents strong oxidizing power, chemical and biological inertness, high stability to photocorrosion in the entire $\mathrm{pH}$ range and low cost. On the other hand, $\mathrm{ZnO}$ with high photocatalytic activity, photo-corrodes at alkaline $\mathrm{pH}$ [6]. However, the main drawback of both catalysts is associated to the large band gap $(3.2 \mathrm{eV})$, which demand activation in the ultraviolet region of the spectra $(\lambda<390 \mathrm{~nm})$. This significantly limits the efficiency under sunlight, which accounts only for $3-5 \%$ below $390 \mathrm{~nm}$ wavelength. In addition, their high rates of electron-hole pairs recombination provoke a low efficiency in the photocatalytic process[7].Several researches have been done preparing new catalyst or modifying titania or $\mathrm{ZnO}$ in order to overcome these limitations[8-11]. The possibility to control structural features has become an interesting challenge in order to synthesize new materials with specific properties to be applied in environmental catalysis. For instance, hierarchical nanostructures based on bismuth oxyhalides (BiOX) have been proposed as new materials for photocatalysis due to their activity in the visible region of the spectra [12-14]. Structurally these materials present tetragonal systems (matlockite-like structure) with $\mathrm{Bi}_{2} \mathrm{O}_{2}$ layers interleaved with two halogen atoms [15]. Particularly, bismuth oxyiodide (BiOI), presenting microsphere morphology, has provoked great interest in heterogeneous photocatalysis because it shows high photocatalytic activity under visible radiation and high degradation yields of a wide class of organic compounds, such as methylene blue, phenol, methyl orange, rhodamine B and sodium pentachlorophenate $[16,17]$. In addition, it has been reported that $\mathrm{BiOI}$ microspheres show higher photoactivity than titanium dioxide Evonik P-25 in the visible range [18-20].

The solvothermal synthesis has been described as the most suitable methodology for BiOI microspheres preparation. The solvothermal conditions, involving high temperature and pressure, modify the physicochemical behavior of the solvent, such as the dielectric constant. In 
consequence, using this methodology it is possible to obtain compounds which under normal conditions of pressure and temperature, cannot be obtained [21].The aim of the present work is to synthesize $\mathrm{BiOI}$ under solvothermal conditions controlling the reaction time. The materials obtained were characterized and their photocatalytic activity measured on caffeic acid solutions. This compound was chosen as a representative phenol structure present in several agro industrial wastes such as winery wastewaters [22].

\section{Experimental}

\subsection{Sample preparation}

The synthesis of bismuth oxyiodide (BiOI) was performed using a solvothermal method. All reagents were of analytical grade (AR) and used as received. An ethylene glycol solution (20 $\mathrm{mL}$, Acros, 99\%), containing $1 \mathrm{mmol}$ of the ionic liquid 1-buthyl-3-methylimidazolium iodide [bmim]I (Sigma-Aldrich, 99.0\%) was added slowly to 1 mmol of $\mathrm{Bi}\left(\mathrm{NO}_{3}\right)_{3} \cdot 5 \mathrm{H}_{2} \mathrm{O}$ (SigmaAldrich, 99.9\%) dissolved in ethylene glycol. The mixture was magnetically stirred at room temperature for 30 minutes and then transferred to a $25 \mathrm{~mL}$ Teflon-coated Parr ${ }^{\circledR}$ steel autoclave. The autoclave temperature was raised to $120^{\circ} \mathrm{C}$. Reactions were stopped at 2, 6, 12, 24, 30 and $48 \mathrm{~h}$. Once each reaction was completed, the autoclave was cooled to room temperature. The products were separated by vacuum filtration and thoroughly washed using distilled water and absolute ethanol (Carlo Erba, 99.9\%). Finally, the materials obtained were dried at $60{ }^{\circ} \mathrm{C}$ during $48 \mathrm{~h}$ in a forced air furnace.

\subsection{Characterization}

The crystalline structure of BiOI powder was studied by X-ray diffraction (XRD) performed in a Bruker D8 diffraction system with $\mathrm{Cu} \mathrm{K} \alpha$ radiation $(\lambda=1.5406 \AA)$ in a 2-theta scan range of $10-80^{\circ}$. The surface morphology was determined by scanning electron microscopy (SEM) in a JEOL instrument operated at $20 \mathrm{kV}$ and using a JSM-6400 computational system. Additionally, 
transmission electron microscopy (TEM) using a JEOL JEM 1200 EX-II operated at $120 \mathrm{kV}$ was recorded for synthesized samples. Energy dispersive X-ray spectroscopy (EDS) was performed with a JSM-6380 LV equipment operated at an accelerating voltage of $10 \mathrm{kV}$. The surface area of the materials was determined by adsorption-desorption isotherms using nitrogen at $77 \mathrm{~K}$ and Brunauer-Emmett-Teller analysis (BET). The pore size distribution was determined though desorption isotherm applying the Barret-Joyner-Halenda method (BJH) and using TriStar II Micromeritics surface Area and Porosity analyzer. The FTIR spectra were obtained using a spectrometer IR Nicolet Nexus with Fourier transform. The diffuse reflectance spectrum (DRS) was obtained using a spectrophotometer Precisely Perkin Elmer Lambda 35 UV/Vis with integrating sphere.

\subsection{Photocatalytic activity}

The photocatalytic activity of synthesized materials was measured following the degradation of caffeic acid. Reactions were performed in the experimental set-up schematized in Figure 1. It consists of a $300 \mathrm{~mL}$ flask refrigerated by tap water. The lamp (Xe VIPHID 6000k, $12 \mathrm{~W}$ ) was placed inside the reactor protected by a borosilicate closed cylinder. The lamp emission ranged between 380 and $900 \mathrm{~nm}$ with a spectrum similar to solar irradiation. Synthesized catalysts and $\mathrm{TiO}_{2}$ Evonik P25 (25 mg each) were added to a caffeic acid solution $\left(250 \mathrm{~mL}, 10 \mathrm{mg} \mathrm{L}^{-1}\right)$ and magnetically stirred in dark during $20 \mathrm{~min}$ to reach the adsorption equilibrium. After that, the lamp was turned on and solution maintained under magnetic stirring. Samples were taken each $20 \mathrm{~min}$ and filtered on a nitrocellulose membrane (Millipore, $0.22 \mu \mathrm{m}$ ) for analysis. The remaining caffeic acid in solution was quantified measuring the absorption at $312 \mathrm{~nm}$ in a Shimadzu UV-1601 PC spectrophotometer and comparing it with a calibration curve done with a standard (Sigma Aldrich 97\%). Mineralization of samples was determined by total organic carbon (TOC) analysis (Shimadzu TOC-V CPH/CPN). 


\section{Results and discussion}

\subsection{SEM and TEM analysis}

In the reaction of bismuth nitrate and ionic liquid [bmim]I in the presence of ethylene glycol, hierarchical microspheres can be formed [23]. In this system, the ionic liquid plays two roles: first, is a source of iodide and second, it acts as a template agent [18]. Also, experiments using KI as iodide source were carried out. Since the shape of these materials were less spherical and present lower surface area and photocatalytic activities are not discussed here. In this work all the solvothermal synthesis of BiOI were conducted at the same temperature $\left(120{ }^{\circ} \mathrm{C}\right)$ varying only the reaction time $(2,6,12,24,30$ and $48 \mathrm{~h})$. Figure 2 depicts the SEM images showing the morphology of the products obtained at different reaction times. It can be seen that structured microspheres are formed even at short periods of reaction $(2 \mathrm{~h})$ obtaining the most regular forms between 12-30 h (Figures2c-e). At higher reaction times ( $48 \mathrm{~h}$ ) some disaggregation of the microspheres can be observed (Figure 2f). The average microspheres size obtained was approximately between 4-5 $\mu \mathrm{m}$. The SEM images confirm that $\mathrm{BiOI}$ materials are constituted by spheres formed by irregular nanosheets connected between them and forming hierarchical microspheres. A verification of this can be observed in Figure $3 \mathrm{a}$ where the nanosheets are clearly shown. The composition of the material is confirmed by the EDS analysis shown in Figure 3b. Only bismuth, iodine and oxygen are evidenced in all the synthesized material. TEM images shown in Figure 4 verify the nanosheet structure of microspheres.

\subsection{Adsorption-desorption analysis}

The pore size distribution was determined by the Barret-Joyner-Halenda (BJH) method. The BJH isotherm shown in Figure 5 describes the $\mathrm{N}_{2}$ adsorption-desorption profiles of the synthesized materials. All the samples exhibit irreversible type IV adsorption isotherms with an H3 hysteresis loop confirming the mesopore structure [24]. All samples exhibited a narrow pore size distribution at around $20 \mathrm{~nm}$, as shown in Figure 5 (inset). Table 1 shows the average values of textural properties of the synthesized materials obtained at different reaction times. It can be seen that the BET surface and pore diameter are uniform. There is no evident correlation between the reaction time and the textural properties. In the Table 1 it can be observed that the only change in the textural features is the BET surface area, increasing between 12 and $24 \mathrm{~h}$. Considering that the temperature and pressure of the reaction system remain constant, changing only the reaction time, it is possible that at times below 12 hours the 
microspheres are being formed, reaching the maximum growth between 12-24 h. At longer periods of reaction the material could suffer sinterization, reducing the BET surface area.

\subsection{X-ray diffraction}

The crystal phase of synthesized bismuth oxyiodides was unambiguously determined through $\mathrm{X}$-ray diffraction on polycrystalline samples. Figure 6 shows the peaks of the synthesized compounds. These phases correspond to the tetragonal system, which is in agreement with JCPDS card 01-073-2026 for BiOI. It should be noted that the first pick, around $7-9^{\circ}$, corresponds to the plane (001). The shift can be explained because when the reaction was carried out at short reaction time the crystals phases are not well defined.

No impurity peaks or presence of other phases were observed. The average size of crystallites can be estimated using the Scherrer formula (Eq. 1) [25].

$$
D=\frac{K \lambda}{B \cos \theta_{B}}
$$

Where $\lambda$ is the wavelength of $\mathrm{X}$-ray radiation $(\lambda=0,15406 \mathrm{~nm}$, for copper), $\mathrm{K}$ is the Scherrer's constant $(\mathrm{K}=0.94), \theta$ is the Bragg angle, $\beta$ is the half width of the peak. The average crystal size is given in Table 1 staying quite constant, around $8.1 \mathrm{~nm}$, for reaction times between 6 to $30 \mathrm{~h}$.

\subsection{FT- IR Analysis}

The composition of BiOI was confirmed through infrared spectra. Figure 7 shows the FTIR spectra of the materials obtained at different reaction times. Signals around 3600 and $1600 \mathrm{~cm}^{-1}$ correspond to $\mathrm{O}-\mathrm{H}$ symmetrical stretching and scissoring, respectively, due to adsorbed water. Peaks at $512 \mathrm{~cm}^{-1}$ and $778 \mathrm{~cm}^{-1}$ are attributed to stretching vibrations of Bi-O. Finally, the signals between $500 \mathrm{~cm}^{-1}$ to $1554 \mathrm{~cm}^{-1}$ are associated to the stretching vibration of the tetragonal crystal links $\mathrm{BiOI}[26,27]$. It is also confirmed the absence of residualethylene glycol and ionic liquid. 


\subsection{Optical properties}

The band gap of the material is a decisive attribute that modulates the activity of the semiconductor in the visible region of the sunlight [28]. The optical properties of the synthesized materials were studied using diffuse reflectance spectroscopy (DRS) in the UV-Vis range. Figure 8 depicts the DRS curves of the BiOI obtained at $12 \mathrm{~h}$ and $24 \mathrm{~h}$ of preparation, from which the band gap were determined. The optical borders of the materials were $590 \mathrm{~nm}$ and $578 \mathrm{~nm}$ for BiOI after $12 \mathrm{~h}$ and $24 \mathrm{~h}$ reaction, respectively. The Eg of the materials were calculated by the Tauc representation, using the equation 2, where $\alpha$ represents the absorption coefficient, $h$ is the Planck constant, $v$ is the radiation frequency, Eg the band gap, and $n$ is related to the indirect transition ( $n=4$ for BiOI) $[29,30]$.

$$
\alpha(h v)=\mathrm{A}(h v-\mathrm{Eg})^{n / 2}
$$

The inset of Figure 8 allows the determination of the band gap directly from extrapolation in the Tauc plot. The values found are 1.95 and 1.98 for materials prepared at 12 and $24 \mathrm{~h}$ in autoclave, respectively. Table 2 reports the values of optical borders and band gap obtained for all the synthesized $\mathrm{BiOI}$, ranging between 1.95 and 2.05, which are similar to those reported in literature [31-33].

\subsection{Photocatalytic activity}

The photocatalytic activity of the synthesized materials was evaluated using caffeic acid as a target molecule. This substrate was chosen because is a well known antioxidant present in the effluents coming from the winery industry. The reaction was conducted under UV-visible radiation and the degradation profiles compared to the catalyst Evonik P25 (former Degussa P25). Reactions were carried out in aqueous suspension during 60 min. Figure 9 depicts the curves of UV-Vis spectra of caffeic acid (10 ppm) and their evolution during the photocatalytic process using the catalyst prepared at 12 hour of autoclave. The most pronounced degradation occurs during the first $20 \mathrm{~min}$ of irradiation. After $60 \mathrm{~min}$ irradiation the changes are less 
significant. The mineralization, measured as total organic carbon, reaches around $50 \%$ using the same catalyst (data not shown). After $1 \mathrm{~h}$ the TOC removal remains almost unchanged. The TOC course can be explained considering the formation of long term intermediates refractory to oxidation. Recently, Augugliaro et al. report the oxidation of phenolic compounds containing carboxylic acid group using $\mathrm{TiO}_{2}$ [34]. They found phenolic intermediates, dicarboxilic and carboxylic acids. Also in homogeneous system (photo-Fenton reaction) the intermediates identified were phenolic compounds and anhydrides formed by condensation reactions [35]. All of these compounds are known as difficult to be oxidized. Figure 10 shows the caffeic acid profiles including the blanks. Photolysis alone does not provoke the decomposition of the caffeic acid (less than $10 \%$ in one hour). In this Figure it can be observed that the materials synthesized by solvothermal procedure present higher catalytic activity than Evonik P25, usually considered as the most active photocatalyst in the UV-Vis region [36-38]. Since that titania and BiOI have similar surface area (52 and $54 \mathrm{~m}^{2} \mathrm{~g}^{-1}$, respectively) their photocatalytic activities can be compared. It is important to indicate the use of wavelengths over $380 \mathrm{~nm}$ for titania is not the best condition for comparison, however our goal is to find the better synthesis conditions for new materials that can be activated exclusively with solar light. The synthesized catalyst provokes degradation extent over $80 \%$ in one hour and the commercial reference P25 does not surpass $55 \%$ in the same period of time. Table 3 gives the degradation extent after $1 \mathrm{~h}$ irradiation and initial constant rates of all the prepared catalysts. It can be concluded that all of them reach higher activities than Evonik P25 being higher than those prepared in autoclave with reaction times below $24 \mathrm{~h}$. Apparently higher times in the autoclave provoke some disaggregation of the structure decreasing the activity. The initial rates of caffeic acid oxidation, calculated using the equation (3), are shown in Table 3 [39]. The initial rates of the materials obtained between to 12 and 24 hours presents the highest activity.

$$
v=-\frac{\mathrm{d}[\text { caffeic acid }]}{\mathrm{dt}}(3)
$$




\subsection{Recycling of the BiOI microspheres}

Consecutive runs of caffeic acid photocatalysis with the Xe lamp using the same catalyst produce the curves presented in Figure 11, where reproducible experiments can be observed. After two consecutive runs using the same catalyst carefully washed the catalytic activity of the BiOI decay slightly in around $10 \%$. The decrease of the catalytic activity can be explained by the mass loss and disaggregation of the sponge structure. The SEM and EDS images recorded after two reaction cycles show that no significant changes occurred in the morphology of the microspheres (not shown). In addition, FTIR spectra and XRD of samples used in two consecutive runs show no significant changes compared to the unused material. This issue is strongly relevant because the potential use of these materials depends on their stability during long periods of time.

\section{Conclusions}

In summary, it was possible to obtain hierarchical BiOI microspheres using the solvothermal route with short periods of reaction times. Among the materials synthesized the best results in catalytic activity correspond to materials prepared between 12 and $24 \mathrm{~h}$ of reaction in autoclave. All the materials prepared present higher activity than EVONIK P25 under UV-Vis illumination.

\section{Acknowledgements}

This work has been developed under financial support of National Founds for Science and Technology (Fondecyt, grant 1130502), National Commission of Science and Tecnology (Conicyt/Anillo PIA (ACT-130) and Conicyt/FONDAP/15110019) Projects. Additionally authors thank REDOC.CTA Project UCO 1202. ACM thanks to CONICYT for doctoral fellowship (63105856) and Convention de Mobilité doctorale (Institut Français $\mathrm{N}^{\circ}$ 18/CUS/2012) 


\section{References}

[1] M.R. Hoffman, S.T. Martin, W. Choi, D.W. Bahnemann, Chem. Rev. 95 (1995) 69.

[2] K. Pirkanniemia, M. Sillanpaa, Chemosphere 48 (2002) 1047.

[3] M. Qamar, A. Muneer, Desalination 249 (2009) 535.

[4] S. Horikoshi, A. Matsubarac, S. Takayama, M. Sato, F. Sakai, M. Kajitani, M. Abe, N. Serpone, Appl. Catal. B: Environ. 99 (2010) 490.

[5] A.J. Attia, S.H. Kadhim, F.H. Hussein, J. Chem. 5 (2008) 219.

[6] L. Zhang, H. Cheng, R. Zong, Y. Zhu , J. Phys. Chem. C 113 (2009) 2368.

[7] S.Y. Lee, S.J. Park, J. Ind. Eng. Chem. 19 (2013) 1761.

[8] J. Nieto, J. Freer, D. Contreras, R.J. Candal, E.E. Sileo, H.D. Mansilla, J. Hazard. Mater. 155 (2008) 45.

[9] R. Hong, T. Pan, J. Qian, H. Li, Chem. Eng. J. 119 (2006) 71.

[10] R.Y. Hong, J.H. Li, L.L. Chen, D.Q. Liu, H.Z. Li, Y. Zheng, J. Ding, Powder Technol. 189 (2009) 426.

[11] Y. Zhao, C. Chen, Y. Wang, H.W. Ma, L. Zang, J. Zhao, J. Phys. Chem. C 112 (2008) 5993.

[12] H. An, Y. Du, T. Wang, C. Wang, W. Hao, J. Zhang, Rare Metals 27 (2008) 243.

[13] X. Chang, J. Huang, C. Cheng, Q. Sui, W. Sha, G. Ji, S. Deng, G. Yu, Catal. Commun. 11 (2010) 460.

[14] X. Zhang, Z.H. Ai, F.L. Jia, L.Z. Zhang, J. Phys. Chem. C 112 (2008) 747.

[15] X. Xiao, W.D. Zhang, Mater. Chem. 20 (2010) 5866. 
[16] Y.P. Wei, Q.L. Yang, L. Guo, Prog. Chem. 21 (2009) 1734.

[17] X.F. Chang, J. Huang, Q. Tan, M. Wang, G.B. Ji, S.B. Deng, G. Yu, Catal. Commun. 10 (2009) 1957.

[18] Y. Li, J. Wang, H. Yao, L. Dang, Z. Li, J. Mol. Catal. A: Chem. 334 (2011)116.

[19] J.X. Xia, S. Yin, H.M. Li, H. Xu, L. Xua, Q. Zhang, Colloid Surface A: Physicochem. Eng. Asp. 387 (2011) 23.

[20] X. Shi, X. Chen, X. Chen, S. Zhou, S. Lou, Mater. Lett. 68 (2012) 296.

[21] R.I. Walton, Chem. Soc. Rev. 31 (2002) 230.

[22] M. Akassou, A. Kaanane, A. Crolla, C. Kinsley, Water Sci. Technol. 62 (2010) 475.

[23] Y. Wang, L. Zhang, J. Phys. Chem. C 115 (2011) 14300.

[24] K. Sing, D.H. Everett, R. Haul, L. Moscou, R.A. Pierotti, J. Rouquerol, T. Siemieniewska, Pure Appl. Chem. 57 (1985) 603.

[25] D.M. Smilgies, J. Appl. Crystallogr. 42 (2009) 1030.

[26] J. Cao, X. Li, H. Lin, S. Chen, X. Fu, J. Hazard. Mater. 239 (2012) 316.

[27] Z. Liu, X. Xu, J. Fang, X. Zhu, J. Chu, B. Li, Appl. Surf. Sci. 258 (2012) 3771.

[28] A.B. Murphy, Sol. Energ. Mat. Sol. C 91 (2007) 1326.

[29] J. Tauc, R. Grigorovici, A. Vancu, Phys. Stat. Solid. 15 (1966) 627.

[30] D.L. Wood, J. Tauc, Phys. Rev. B 5 (1972) 3144.

[31] Y.Q. Lei, G.H. Wang, S.Y. Song, W.Q. Fan, M. Pang, J. Tang, H. Zhang, Dalton Trans. 39 (2010) 3273.

[32] R. Hao, X. Zuo, X. Xiao, J. Nan, W. Zhang, J. Hazard. Mater. 209 (2012) 137. 
[33] M. Su, C. He, L. Zhu, Z. Sun, C. Shan, Q. Zhang, D. Shu, R. Qiu, Y. Xiong, J. Hazard. Mater. 229 (2012) 72.

[34] A. V. Augugliaro, G. Camera-Roda, V. Loddo, G. Palmisano, L. Palmisano, F. Parrino, M. A. Puma, Appl. Catal. B: Environ. 111- 112 (2012) 555.

[35] M. Antolovich, D.R. Bedgood jr., A.G. Bishop, D. Jardine, P.D. Prenzler and K. Robards, J. Agric. Food Chem. 52 (2004) 962.

[36] M.A. Henderson, SurSR 66 (2011) 185.

[37] U.I. Gaya, A.H. Abdullah, J. Photochem. Photobiol. C 9 (2008) 1.

[38] M.N. Chong, B. Jin, C. Chow, C. Saint, Wat. Res. 44 (2010) 2997.

[39] H.L Pardue, Anal. Chim. Acta 216 (1989) 69. 
Table 1. Textural features for different reaction times at $120^{\circ} \mathrm{C}$

\begin{tabular}{cccc}
\hline Time $(\mathrm{h})$ & $\mathrm{BET}\left(\mathrm{m}^{2} / \mathrm{g}\right)$ & Pore diameter $(\mathrm{nm})$ & Crystal size $(\mathrm{nm})$ \\
\hline 2 & 48 & 19,0 & 3,9 \\
6 & 47 & 21,4 & 8,1 \\
12 & 54 & 19,0 & 8,1 \\
24 & 58 & 18,6 & 8,1 \\
30 & 44 & 23,4 & 8,1 \\
48 & 42 & 24,6 & 4,0 \\
$\mathrm{TiO}_{2} \mathrm{P}-25$ & 52 & 6,9 & - \\
\hline
\end{tabular}


Table 2. Optical features of synthesized $\mathrm{BiOl}$ materials at $120 \stackrel{\circ}{ } \mathrm{C}$

\begin{tabular}{ccc}
\hline Time $(\mathrm{h})$ & Optical borders $(\mathrm{nm})$ & $\mathrm{Eg}(\mathrm{eV})$ \\
\hline 2 & 570 & 2,00 \\
6 & 580 & 2,05 \\
12 & 590 & 1,95 \\
24 & 578 & 1,98 \\
30 & 582 & 2,00 \\
48 & 585 & 2,05 \\
$\mathrm{TiO}_{2} \mathrm{P}-25$ & - & 3,20 \\
\hline
\end{tabular}


Table 3.Photocatalytic activity of synthesized $\mathrm{BiOl}$ at $120 \stackrel{\circ}{\mathrm{C}}$ expressed as degradation percent after 1 hour illumination with Uv-Vis light and initial rate

\begin{tabular}{ccc}
\hline Time $(\mathrm{h})$ & Degradation (\%) & Initial rate $\left(\mathrm{mg} \mathrm{L}^{-1} \mathrm{~min}^{-1}\right)$ \\
\hline 2 & 81,2 & 0,0260 \\
6 & 83,0 & 0,0264 \\
12 & 85,5 & 0,0273 \\
24 & 84,7 & 0,0268 \\
30 & 76,8 & 0,0241 \\
48 & 76,2 & 0,0211 \\
$\mathrm{TiO}_{2} \mathrm{P}-25$ & 53,0 & 0,0095 \\
\hline
\end{tabular}




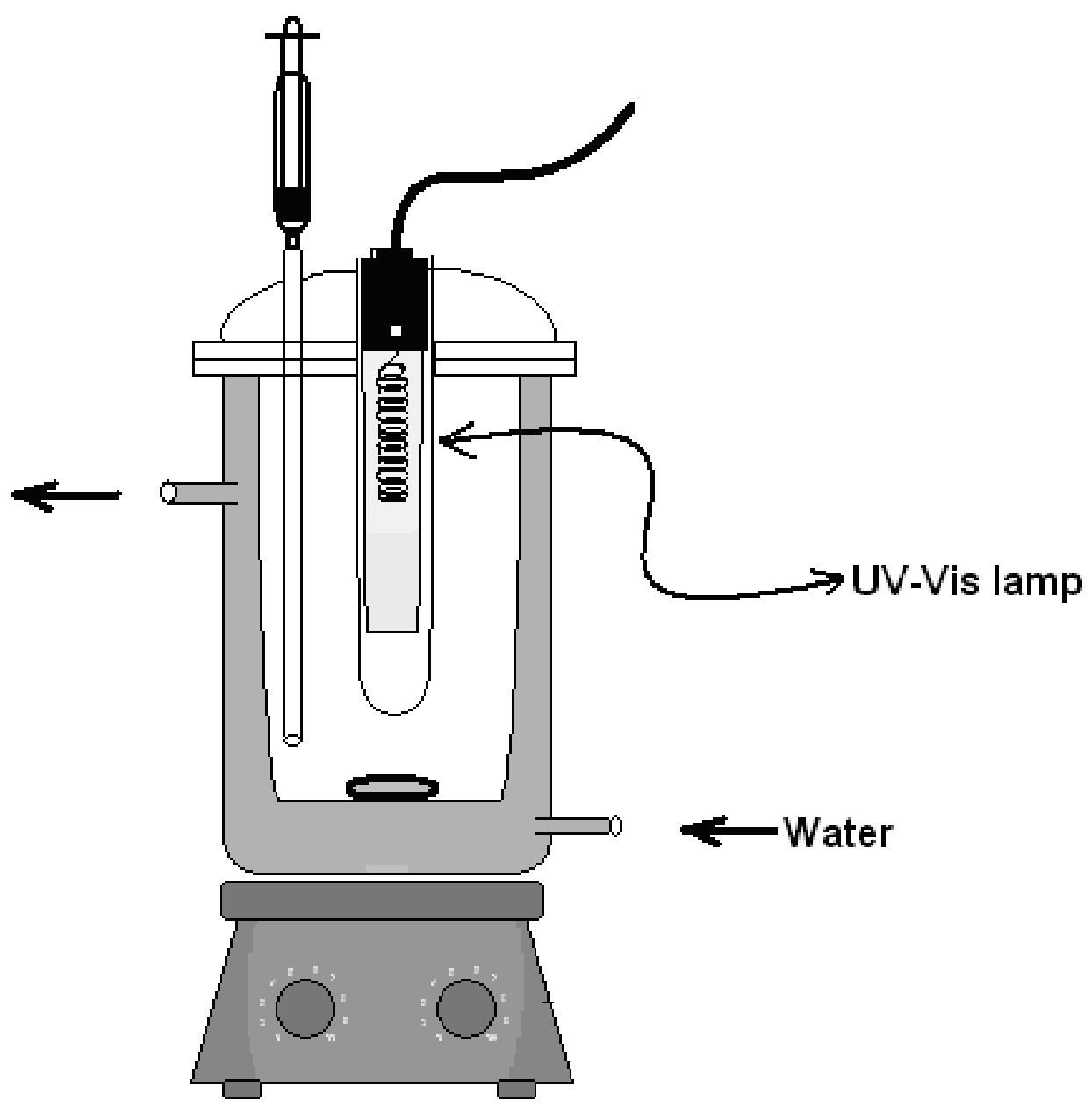

Figure 1. Experimental setup used during the photocatalytic tests 
FIGURE 2

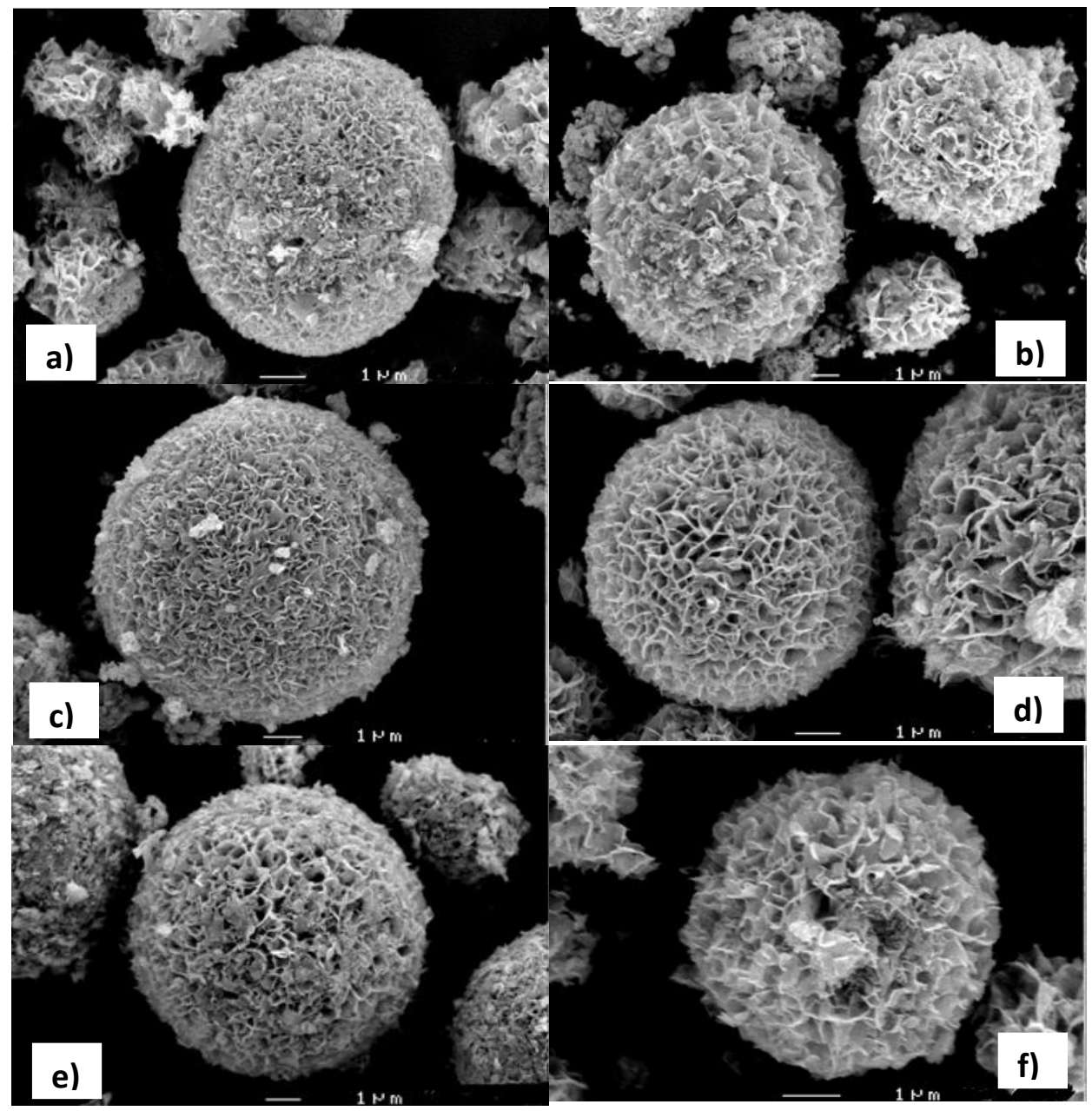

Figure 2.SEM images of BiOI microspheres synthesized for a) $2 \mathrm{~h}$, b) $6 \mathrm{~h}, \mathrm{c}) 12 \mathrm{~h}$, d) $24 \mathrm{~h}$, e) $30 \mathrm{~h}, \mathrm{f}) 48 \mathrm{~h}$. 
FIGURE 3
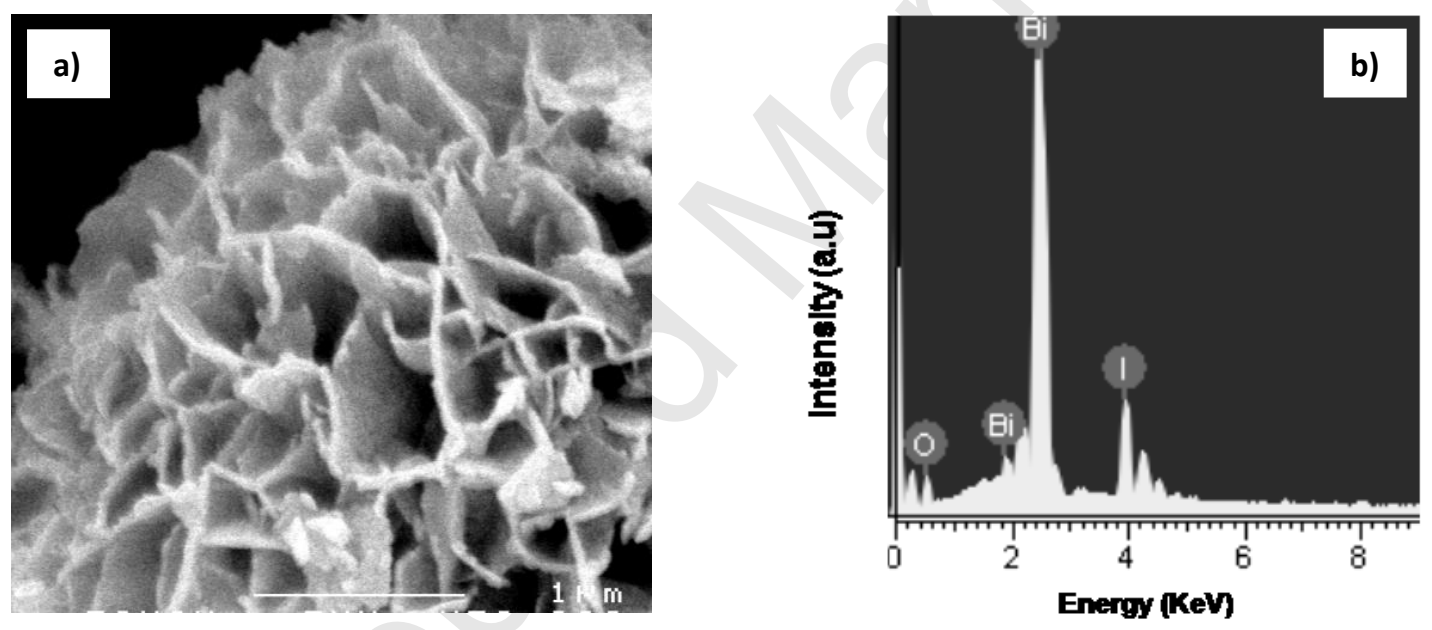

Figure3. a) Expanded SEM image of the BiO microspheres of synthesized for $24 \mathrm{~h}$. b) EDS of BiOl microspheres synthesized for $24 \mathrm{~h}$. 
FIGURE 4

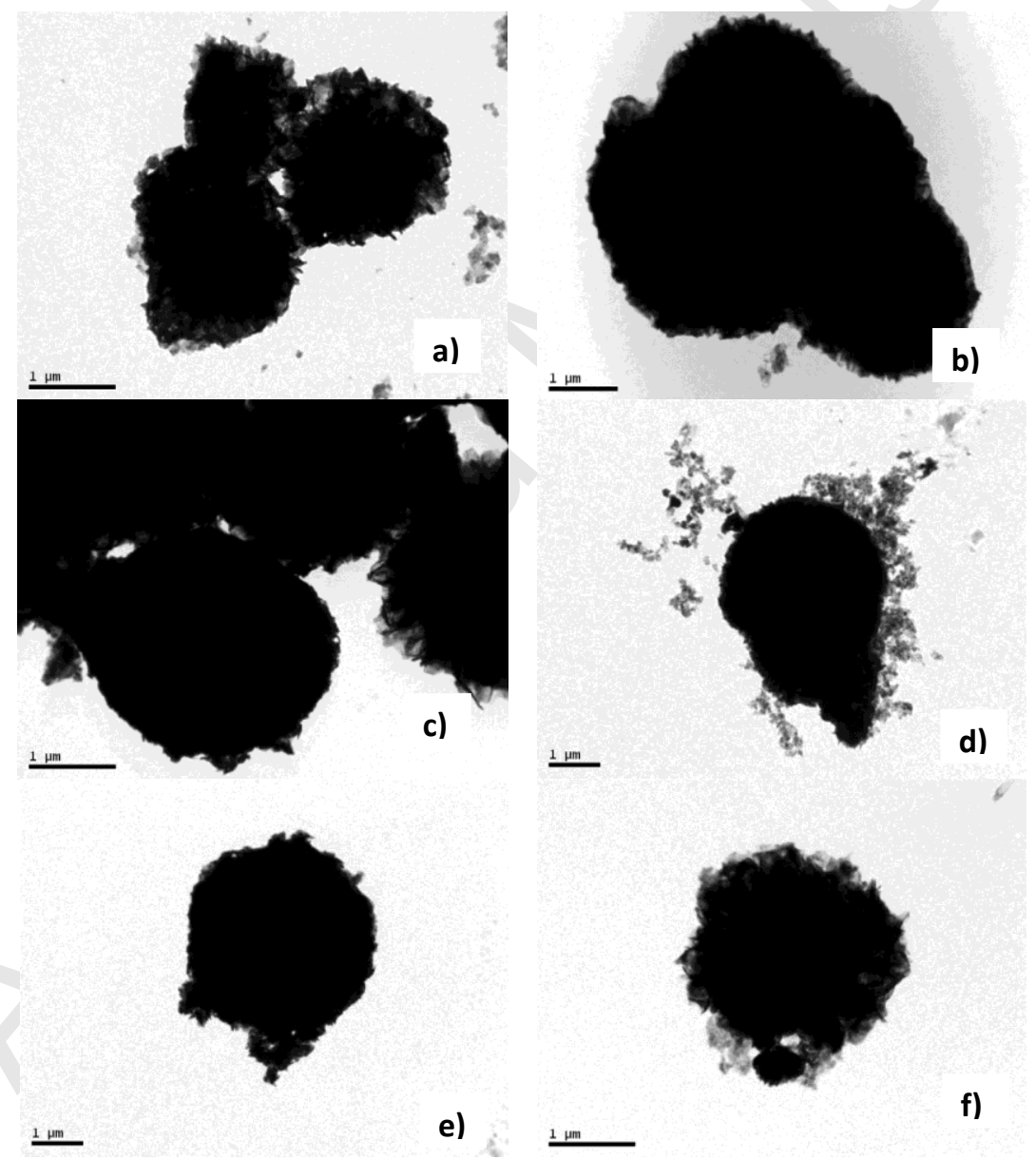

Figure 4.TEM images of BiOl microspheres synthesized for a) $2 \mathrm{~h} \mathrm{~b}$ ) $6 \mathrm{~h} \mathrm{c}$ ) $12 \mathrm{~h}$ d) $24 \mathrm{~h} \mathrm{e)} 30 \mathrm{~h}$ f) $48 \mathrm{~h}$. 
FIGURE 5

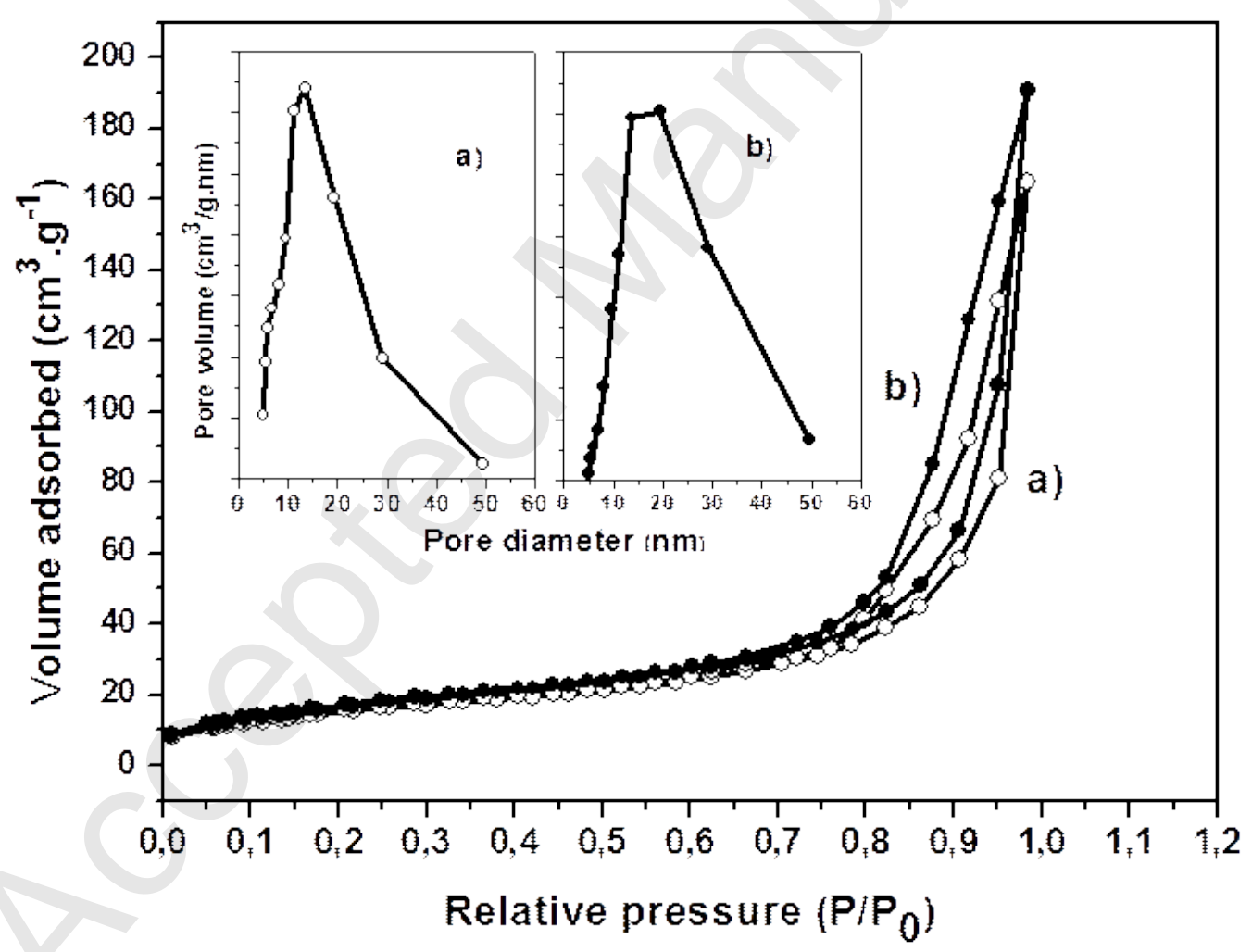

Figure 5.Nitrogen adsorption-desorption isotherms and corresponding pore size distributions curve (insets) of BiOI microspheres synthesized for a) $12 \mathrm{~h} \mathrm{~b}$ ) $24 \mathrm{~h}$. 
FIGURE 6

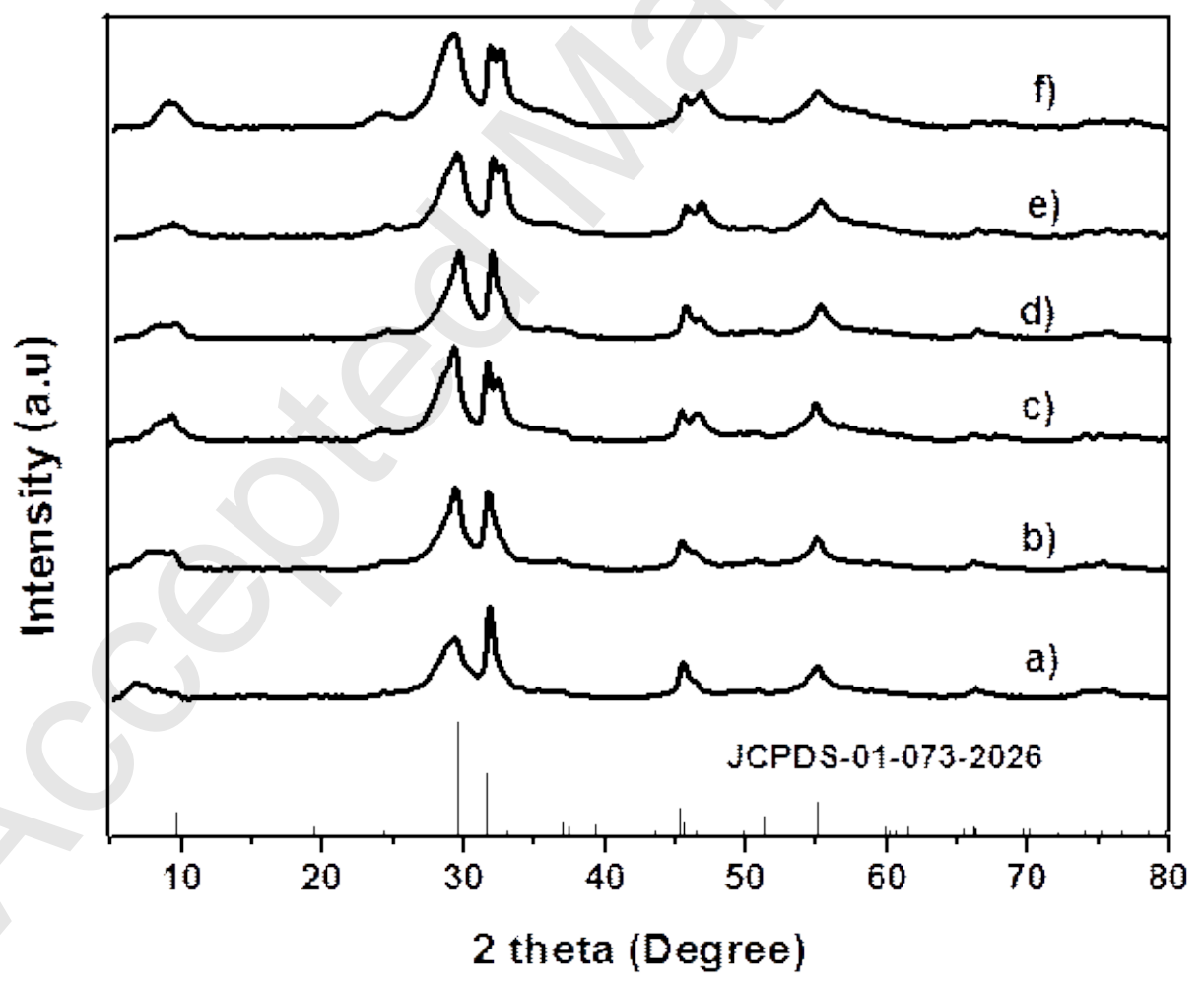

Figure 6. XRD pattern of the BiOI microspheres synthesized for a) $2 \mathrm{~h} \mathrm{~b}$ ) $6 \mathrm{hc}$ ) $12 \mathrm{~h} \mathrm{~d}$ ) $24 \mathrm{~h}$ e) $30 \mathrm{~h}$ f) $48 \mathrm{~h}$. On the bottom, for comparison, pattern of the JCPDS file for BiOI 
FIGURE 7

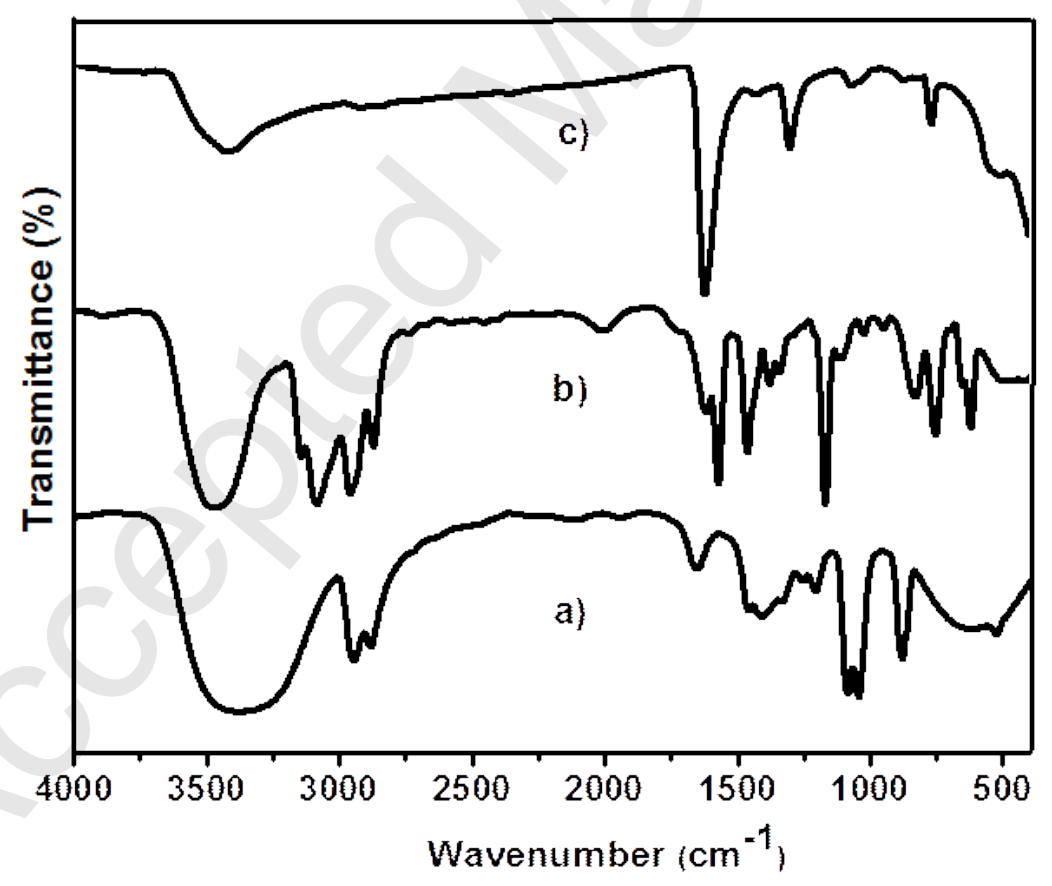

Figure7. IR Spectra a) Ethylene glycol, b) ionic liquid [bmim], c) BiOI Microspheres synthesized for $12 \mathrm{~h}$ with [bmim]. 
FIGURE 8

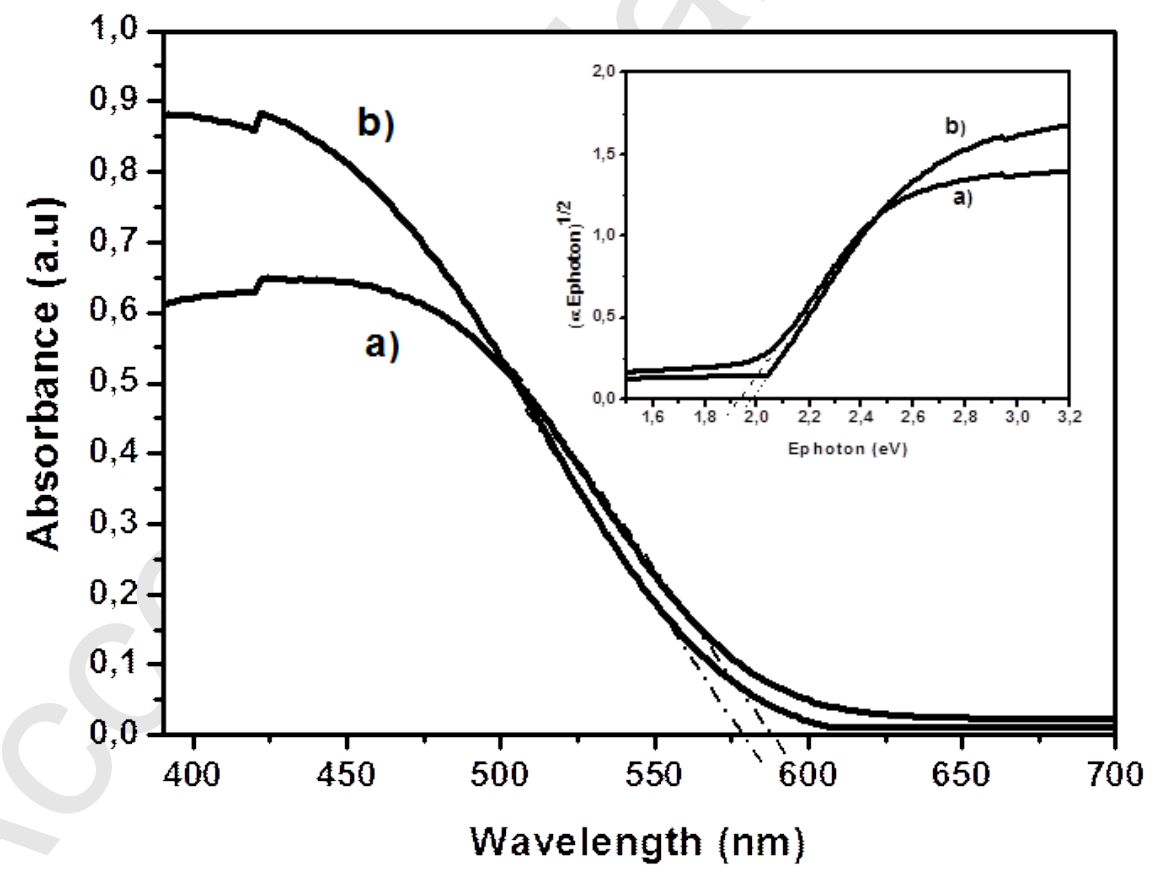

Figure8. UV-vis diffuse reflectance spectra (DRS) for reactions of a) $12 \mathrm{~h}$ and b) $24 \mathrm{~h}$. Inset: Tauc plot $(\alpha h v)^{1 / 2} v s h v$. 
FIGURE 9

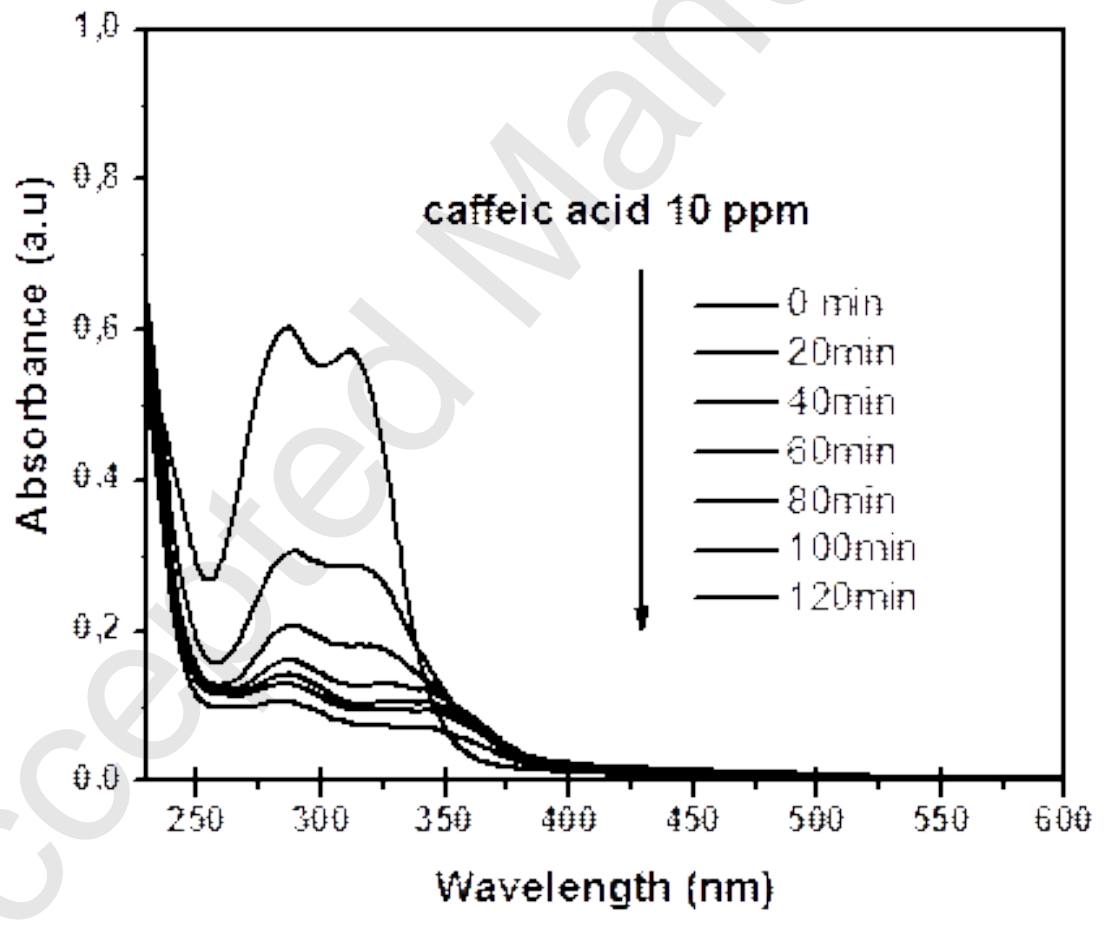

Figure9. UV-vis spectra during the degradation of caffeic acid in presence of BiOI microspheres synthesized for $12 \mathrm{~h}$. 
FIGURE 10

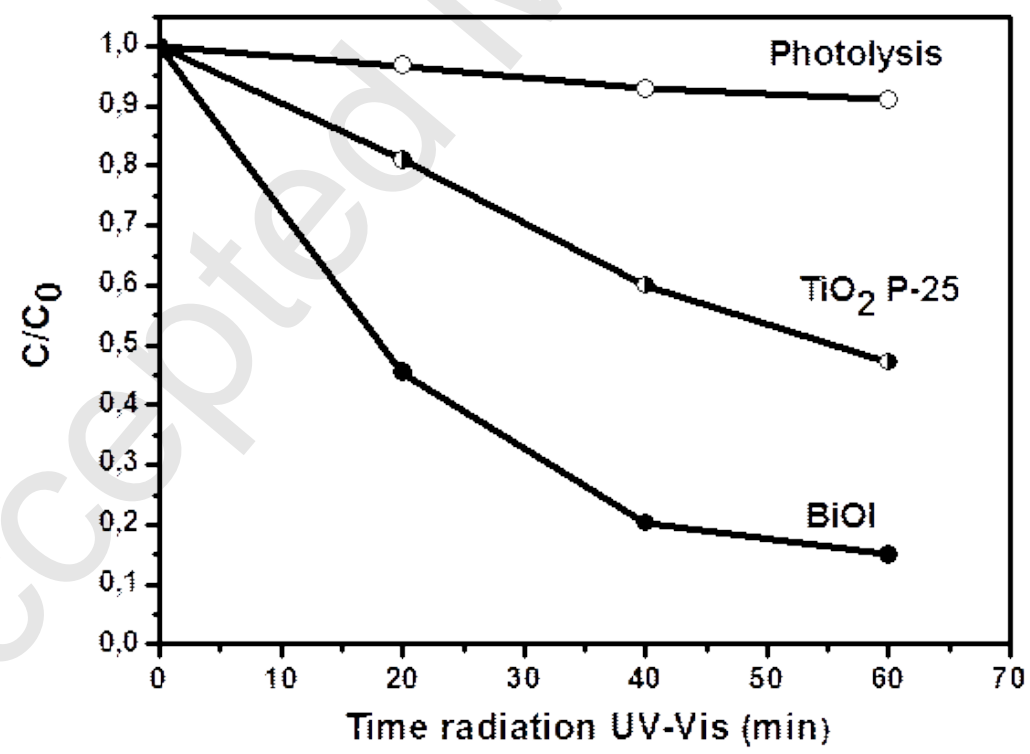

Figure10. Degradation profiles of caffeic acid in the presence of BiOl synthesized for $12 \mathrm{~h}$, Evonik $\mathrm{TiO}_{2}$ P25 and direct photolysis. 
FIGURE 11

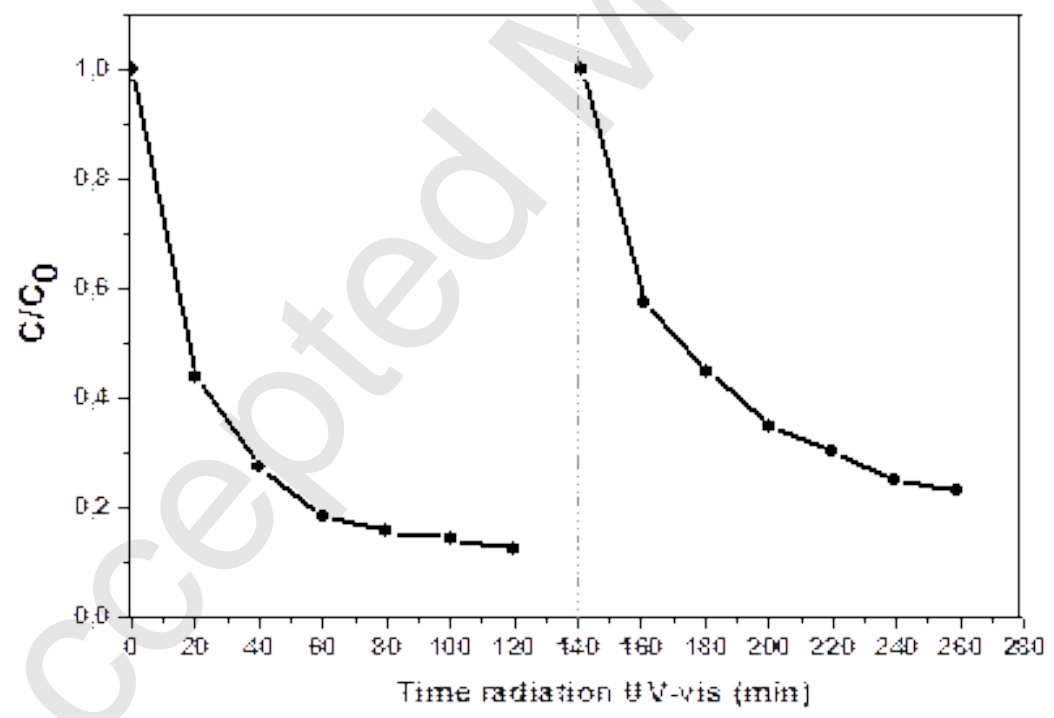

Figure 11. Recycling of microspheres synthesized for $12 \mathrm{~h}$. 


\section{HIGHLIGHTS}

$\checkmark$ The effect of the reaction time on the morphology of BiOI microspheres was studied

$\checkmark$ The structural characterization of the catalyst was carried out

$\checkmark$ The activity of materials was evaluated on caffeic acid and compared to titania Evonik P25 under simulated solar light

$\checkmark$ BiOI presents higher activity that titania P25 


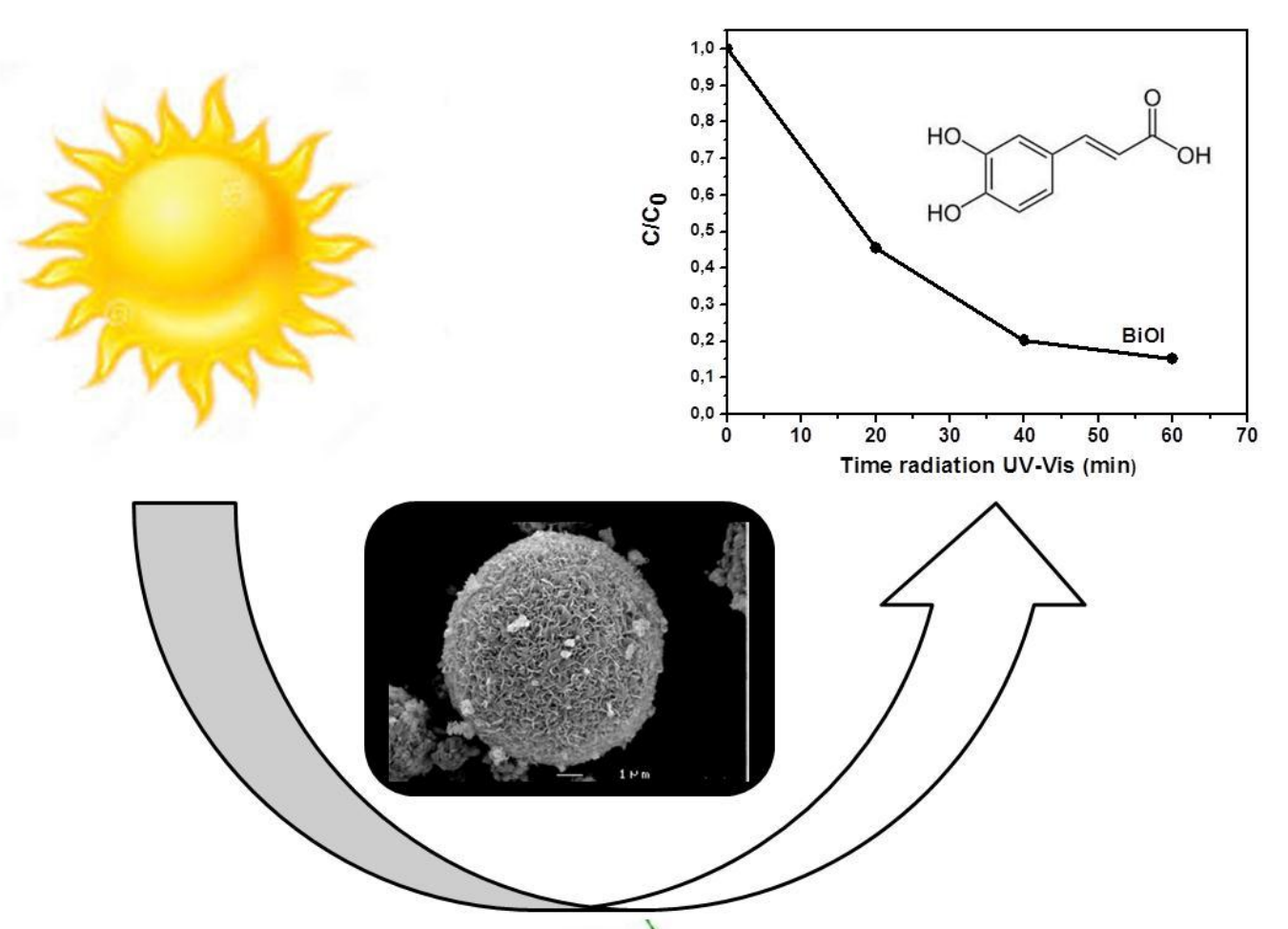

